\title{
Original Quarter One Projects Utilizing Rapid Prototyping
}

\author{
Bruce A. Feodoroff \\ New England Institute of Technology
}

\begin{abstract}
This paper describes the success New England Institute of Technology (NEIT) is experiencing in grabbing hold of the first quarter students' creative energy and motivating them to succeed in Mechanical Engineering Technology. The introduction and use of a rapid prototype machine has significantly impacted not only the quality of the resulting original project models or prototypes but has greatly enhanced the learning experience for quarter one (freshmen) students. This has helped in sustaining the students' interest in Mechanical Engineering Technology throughout the program.
\end{abstract}

Introduction

New England Institute of Technology is a private, non-profit technical college founded in 1940 that provides over 29 specialized associate and bachelor degree programs that prepare students for technical careers. Most associate degree programs can be completed in 18 months, and Bachelor of Science programs in 3 years. The academic year is divided into four (4) ten week quarters with a six week intersession period during June and July. NEIT's open enrollment policy requires entering students to be assessed for skill in reading, writing and mathematics to determine their readiness to begin standard college work. NEIT offers technical programs that meet the career-oriented needs of students with emphasis placed on hands-on training.

Students at the associate in science level of the Mechanical Engineering Technology (MCT) program concentrate on Product Design. They study the design of the products by learning design principles, sketching, problem solving, and how both engineering materials and manufacturing processes and machines are selected and scheduled. Design is emphasized utilizing the latest in computer drafting technology.

The Bachelor of Science in Mechanical Engineering Technology focuses on product and process design, tool and machine design, and manufacturing methods, and technical problem solving.

MCT Quarter One Courses

During the first quarter, MCT students are enrolled in an introductory engineering course, (MCT112 Introduction to Mechanical Engineering Technology), a design principles course (MCT113 Design Principles), and a computer aided design course (MCT115 CAD I). 
The introductory engineering course provides an overview of the engineering profession with sample applications of the typical duties, tasks, and environment of the engineer and technologist A review of the fundamental skills needed to succeed in the MCT program are also covered.

The design principles course introduces the students to methods and procedures for design and product development. Basic principles and approaches to design are covered with emphasis on concept generation, prototyping and testing, reverse engineering, and other approaches used in product development.

The computer aided design course utilizes a three-dimensional parametric solid modeling software package that allows students to immediately create "solid" objects in virtual reality. Emphasis is placed on design intent.

It is within the design principles course that first quarter students are challenged on the first day of class with a course requirement to design and create a model or prototype of a "new product" or re-engineer an existing product in nine weeks and to present their creation during the final class session. Students may choose to work alone or as part of a two-member team. The complexity and quality of the results of these projects has been greatly enhanced by the use of a relatively inexpensive rapid prototyping machine. This approach differs from institutions that give freshmen a list of topics or projects to choose from, or provide a set of well-defined design projects that are to be completed in a predetermined sequence, or provide a container with "components" from which students are required to fulfill a specified task ${ }^{1,2,3}$. At NEIT, on that first day of class, students are asked to come up with five great ideas for a new product. During the second class, a student may be assigned a team partner. At this point each team has ten (10) great ideas for new products. Before the second class is dismissed, each team must select and present to the rest of the class the project they will be working on. The project can't be something that is trivial and there must be reasonable expectation that the project can be completed within the allotted time frame.

\section{D Modeling}

We live in a three-dimensional world. Consequently, it is not a big surprise that students (and most other people) have difficulty with visualizing two-dimensional orthographic projections of three-dimensional objects onto a two-dimensional plane whether it is on a flat drafting table or if it resides in virtual reality and appears on a computer monitor. It is equally difficult to create in your mind what a three-dimensional object will look like given only the two-dimensional orthographic projections of the object placed on a mechanical drawing. Add to this problem the difficultly of communicating design intent and we can understand why most engineering students experience a great deal of frustration and a loss of interest with courses dealing with graphical design.

The current three-dimensional parametric solid modeling software packages (AutoDesk Inventor $\rightarrow$, SolidWorks $\rightarrow$, ProE's Wildfire $\rightarrow$, and others) are very user friendly and greatly facilitate the graphical design process. ${ }^{4}$ At one time, the slide rule was an essential tool all engineering students had to learn to use. Today, the ability to utilize one of these threedimensional parametric solid modeling packages has become just another one of the standard 
tools acquired by mechanical engineering graduates. In October 2004, a fundamental change occurred in the method of instruction used in the first quarter graphical design course at NEIT by introducing students to a 3-D solid modeling software package instead of a 2-D CAD software package. Instead of being concerned with which one of three possible ways of defining and inputting the length and direction of a single line on 2-D drawing, students are creating 3-D objects. Students rapidly acquired the ability to navigate around the different toolbars of the 3-D software package. The instructors had trouble staying ahead of the students. In the past, the first quarter graphical design course was focused more on how to use the software and less on actual design of mechanical parts. With the changeover to a 3-D parametric solid modeling software package, the situation quickly changed from one in which the instructor led the students to one in which the students pressured the instructor to accelerate the content and scope of the material covered.

Today, Quarter One Mechanical Engineering Technology students are introduced to graphical design utilizing a three-dimensional solid modeling package that allows students to immediately create "solid" objects in "virtual reality" (the object actually resides in the computer's memory in the form of binary code). Again, the focus is on design intent. Students first sketch the main feature of the object and immediately create a virtual 3-D objective. Subsequently, additional features are added to the objective. The actual dimensioning of the features of the created object can be done much later. The software will eventually create the 2-D projected images. "Solid modeling techniques, which stress the design intent of the model, enhance the skill set of freshman engineers and excite their interest on the mechanical engineering process."

The rotation of three-dimensional objects in virtual reality, displayed on a computer monitor, is not only marvelous and thrilling but it gives the students immediate and satisfactory feedback of their work. But, something is missing. Do these images truly communicate design intent? Nothing can replace a three-dimensional solid object sitting in the palm of one's hand to convey design intent. Consequently, the ultimate goal is the creation of a solid model or prototype of the student's creation.

With their limited experience and knowledge, the actual fabrication of a solid model or prototype is not easy for quarter one students. Typically, the results are of poor quality, constructed from cheap materials (cardboard, Styrofoam, duct tape, and glue), and physically not functional (can not support a physical load). Advances in rapid prototyping technology (RPT) have produced relatively inexpensive three-dimensional printers that allow students to "print" what they have created within a three-dimensional computer aided design system (CAD). A number of rapid prototyping techniques can produce fully functional models or parts ${ }^{6}$. In the same way a handheld calculator has accelerated mathematical computation and word processors facilitate generating written reports, rapid prototyping machines have made easy the creation of models and prototypes ${ }^{7,8}$.

NEIT has acquired a Stratasys Dimension 3D printer that uses a fused deposition modeling technique that deposits ABS plastic. Throughout the program, any instructor may use this machine to produce design models for Mechanical Engineering Technology students.

Quarter One Design Projects

Proceedings of the 2005 American Society for Engineering Education Annual Conference \& Exposition 
"First-year engineering design projects are an integral part of the education process in engineering and engineering technology." Design projects are fundamental in developing interest in engineering and technology disciplines ${ }^{2,3,9}$. At NEIT, design projects are utilized throughout the Mechanical Engineering Technology program.

The fundamental goals of quarter one projects is to give the students an introduction to their chosen course of study, a feeling for the extent or scope of the discipline, a chance to engage is a problem solving activity, and an opportunity to participate as a member of a team. These projects also help develop rapport with faculty members and connectivity with the college or institution. There are other goals that can be identified and listed ${ }^{10,11,12}$, but; more importantly, these projects provide a means to "grab" hold of the student's interest in their chosen discipline and to motivate students to utilize their own creative energy to develop a sustaining interest in the discipline.

At NEIT, Quarter One Mechanical Engineering Technology students have always been given the tools needed (Principles of Design and the latest CAD software systems) to facilitate the creation of original new products or the improvement of existing products. But, the results had been mediocre until the introduction of a rapid prototype machine or three-dimensional printer.

After printing the design on the rapid prototype machine and holding the part in his or her hand, the student might suddenly realize that what looked so good in virtual reality doesn't actually satisfy design intent, multiple parts don't fit together well, or a positive image for lettering will produce better results than a negative image. Students are realizing that they can always improve on their design. They are spending more time in the lab reworking their own design on one of the CAD systems. They are pushing their CAD instructors to learn how to add more complicated features to their designs. The rapid prototype machine is experiencing more than fifty (50) hours of machine run-time each week. For many students, the instructor has to force the students to finalize their designs and stop making changes in order to complete the project in the allotted time as they would be requires to do on the job.

Many students use the results of their quarter one design project as the bases for their quarter six (sophomore) project that requires more extensive mechanical design content. One particular student originally designed a toothbrush holder that prevents the toothbrush from becoming contaminated while being stored between uses. For his quarter six project, this student expanded on his design by placing the top of the holder even with the top of a bathroom sink, adding a source of hot water, a source of sanitizing fluid, a drain, and a means to vibrate the holder.

Figure one below shows a very simple custom designed wrench made by a student to remove an oil filter from his motorcycle. This wrench was made before the introduction of the rapid prototyping machine. It is not very impressive. In order to receive a reasonable grade, the student had to give a final poster board presentation. After the installation of the 3D printer, this student asked to redesign the wrench and produced the results shown in figure two. This wrench sells itself. After seeing the new and improved wrench, an instructor from another department had one made for uses on his own boat. 


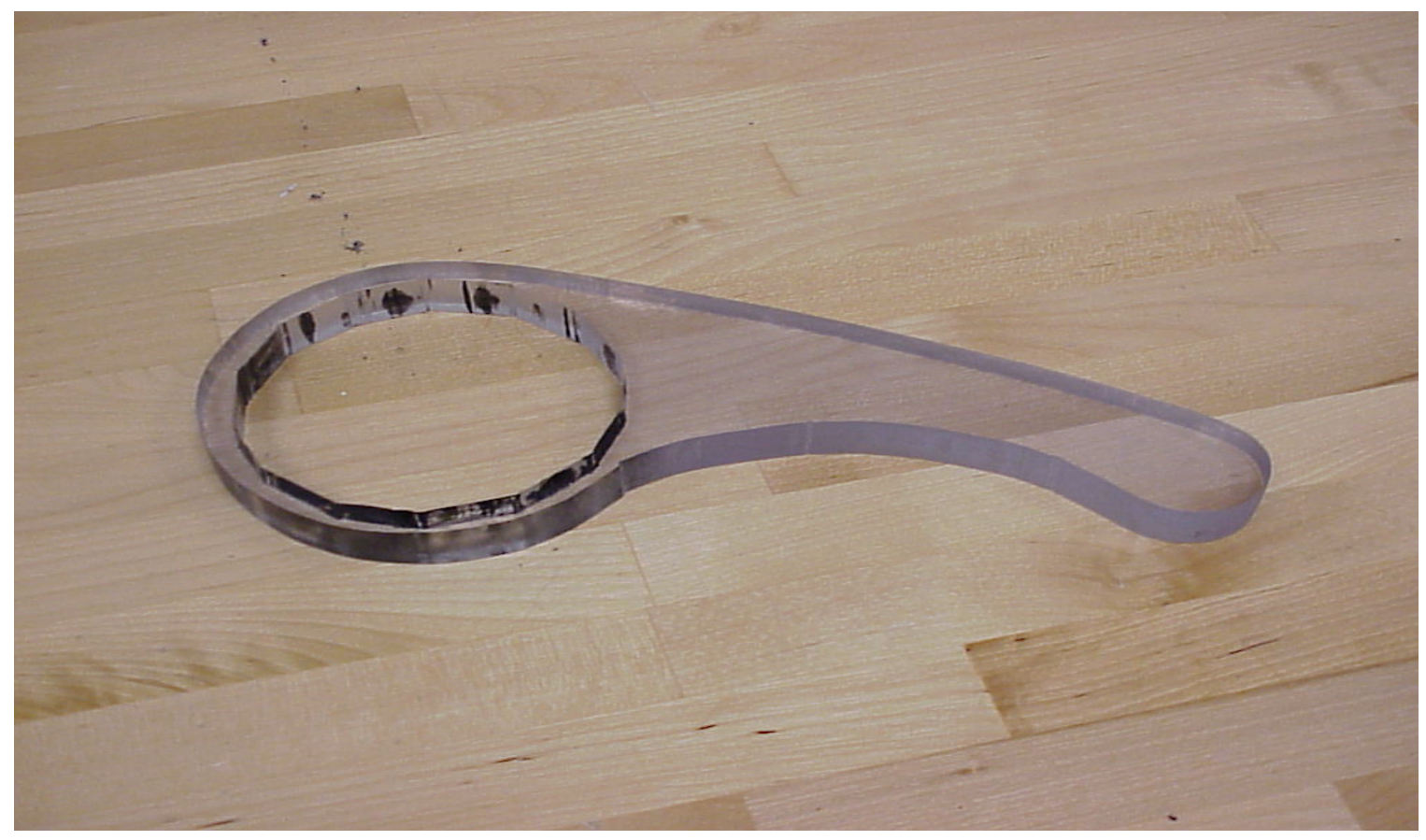

Figure One

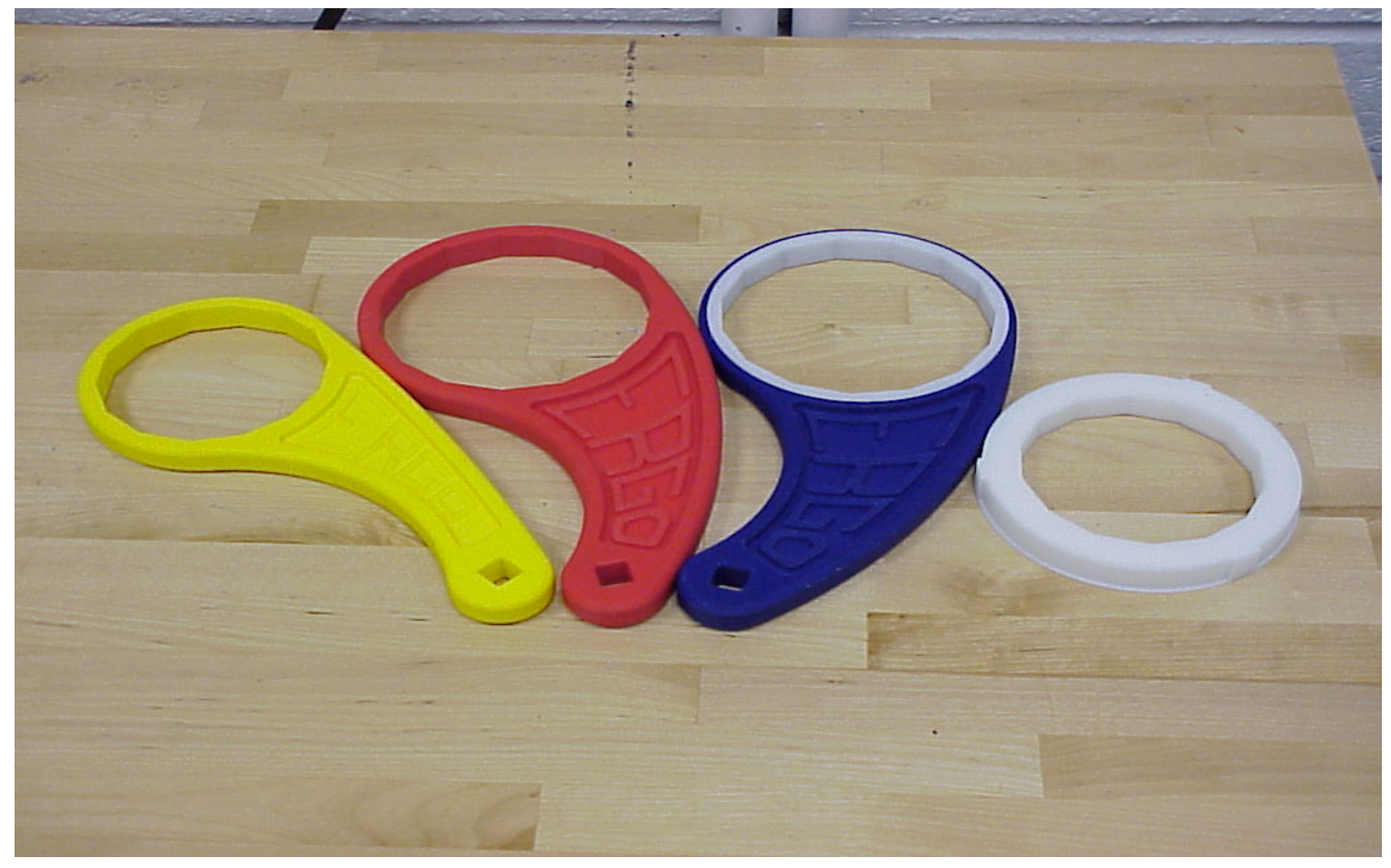

Figure Two

Proceedings of the 2005 American Society for Engineering Education Annual Conference \& Exposition Copyright $\vee 2005$, American Society for Engineering Education 
Another Quarter One student has created the "Lock it, Socket" that prevents his younger brother from removing an electrical plug from and outlet (Figure Three)

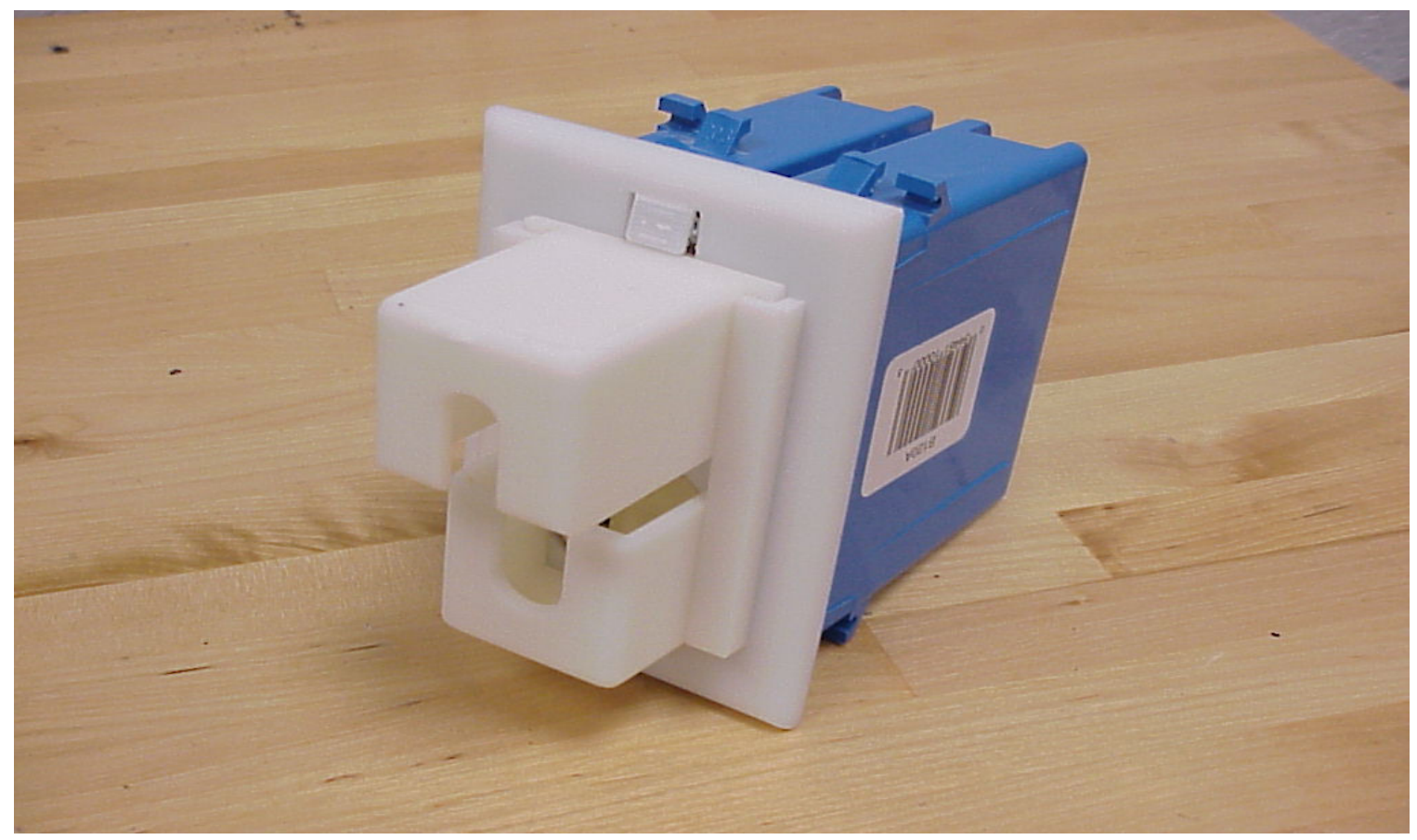

Figure Three

Figure four shows an inhaler redesigned by an adult student so that his young daughter can more easily medicate herself.

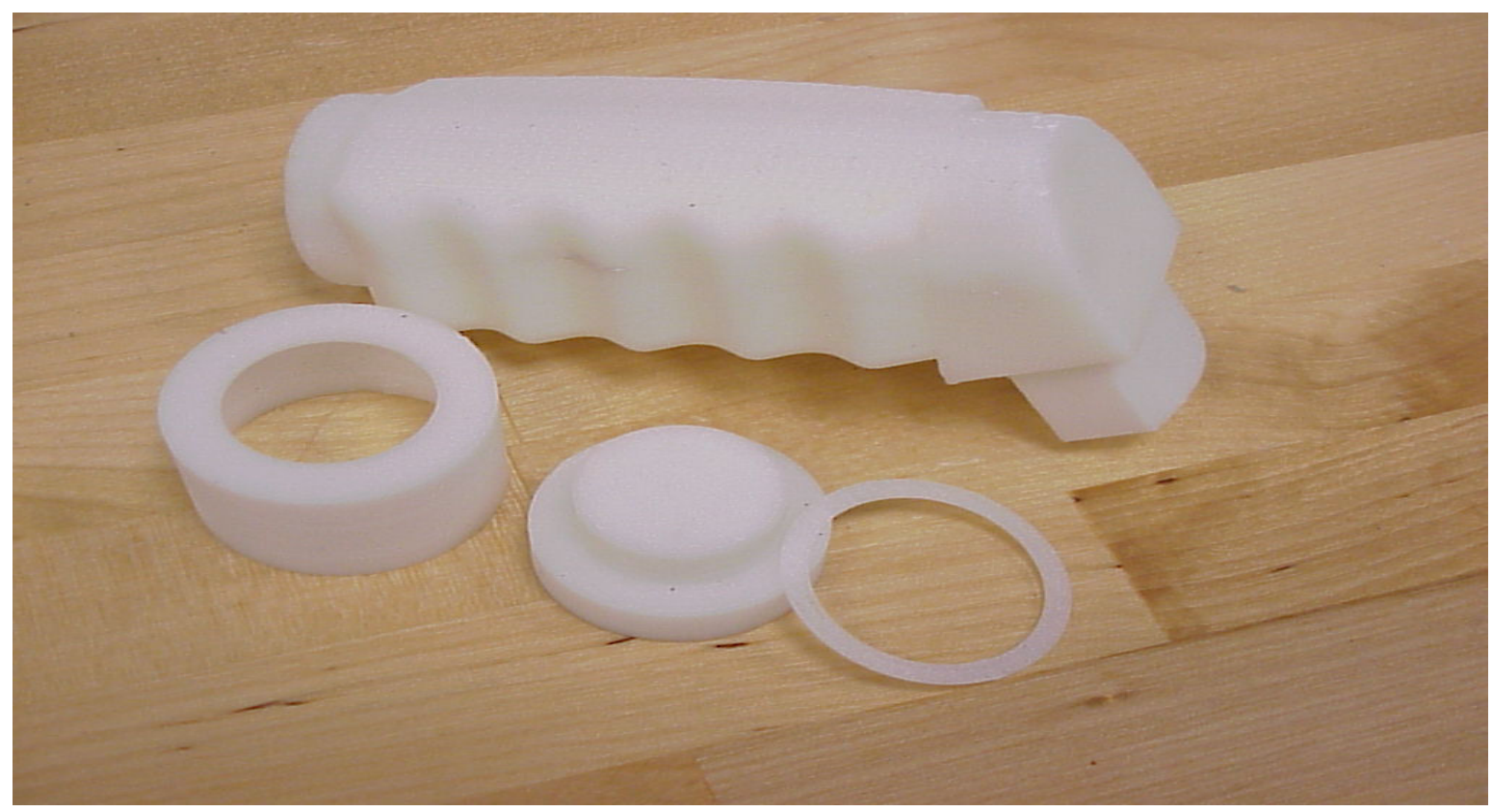

Figure Four

Proceedings of the 2005 American Society for Engineering Education Annual Conference \& Exposition

Copyright $\vee 2005$, American Society for Engineering Education 


\section{Conclusion}

The use of a rapid prototype machine or three dimensional printer has significantly impacted not only the quality of the completed models or prototypes created by Quarter One students, but has greatly enhanced the learning experience. It has motivated students to create more complete and complex designs and to spend more time using the CAD software. Students are no longer satisfied with their "first design". They are encouraged to redesign their creation again and again. It has promoted student interest in mechanical engineering technology. Since the introduction of this machine, the enrollment in the program has increased by more than thirty percent.

\section{References}

1. Hansberry, Eric, Bernard Hoop, Thomas Hulbert, and Robert Augus, "First-Year Design Projects in Engineering Graphics", Proceedings of the 2000 ASEE Annual Conference, St. Louis, Missouri.

2. Skurka, Carolyn, Brain Thomas, and Walter L. Bradley, "Teaching Freshman Engineering Using Design Projects and Laboratory Exercises To Increase Retention", Proceedings of the 2004 ASEE Annual Conference \& Exposition, Salt Lake City, Utah

3. Mountain, Jeffery R., "Method and Experimental Based Design: An approach to Freshman And Sophomore Engineering Design Projects", Proceedings of the 2001 ASEE Annual Conference \& Exposition, Albuquerque, New Mexico.

4. Anneburg, Lisa, Roger Ferguson, "Freshman Engineering Course Utilizing a 3 D Modeling Tool", Proceedings of the 2001 ASEE Annual Conference \& Exposition, Albuquerque, New Mexico.

5. Zang, Paul H., Dale Eddy, and Judson Singer, "Implementing 3-D Modeling for Engineering Freshman", Proceedings of the 2000 ASEE Annual Conference, St. Louis, Missouri.

6. Tromans, G. P., Workshop: "Rapid Prototyping \& Manufacturing Fundamentals", 2004 Rapid Prototyping and Manufacturing Conference and Exposition, Dearborn, Michigan

7. Crokett, Robert, Martin Koch, and Dan Walsh, "A Freshman Design Using RPT”, Proceedings of the 2004 ASEE Annual Conference \& Exposition, Salt Lake City, Utah

8. Newcomer, Jeffery L., Nicoole L. Hoeksta, Kathleen L. Kitto, and Erik K. Mckell, "Using Rapid Prototyping to Enhance Manufacturing and Plastic Engineering Technology Education”, Spring 2004 Journal of Engineering Technology

9. Yue, Jainping, "Teaching Freshman Engineering Design at a Two-Year College", Proceedings of the 2000 ASEE Annual Conference, St. Louis, Missouri.

10. Bayles, Taryn, Mekkus, Anne M. Spence, and Claudia Morrell, "Improving the Freshman Experience", Proceedings of the 2004 ASEE Annual Conference \& Exposition, Salt Lake City, Utah

11. Craven, Kristine, Scott Wayne, and Al Stiller, "The Freshman Engineering Experience at West Virginia University", Proceedings of the 1999 ASEE Annual Conference, Washington DC

12. "Exploring the Recruiting \& Retention Paradigm: What Works \& What Doesn't", Proceedings of the 1999 ASEE Annual Conference, Washington DC 


\section{Bruce A. Feodoroff}

Bruce A. Feodoroff is an Associate Professor and Chairman of the Mechanical Engineering Technology department at the New England Institute of Technology, Warwick, Rhode Island. He holds a BS degree in Physics, M.Ed with concentration in Physics, MS in Manufacturing Engineering, and MBA in Finance. After more than twenty-six years in industry, he made a career change to become a full time college instructor. 